\title{
Expression and Evaluation of Serological Reactivity of Recombinant TP53 Canine Mammary Tumour Associated Antigen
}

\author{
Shumaila Khan ${ }^{1,2}$, Sonal Saxena ${ }^{1}$, Poonam Singh $^{2^{*}}$, Nupur Dutta ${ }^{1}$, \\ Sameer Srivastava ${ }^{1}$, Purnima Gogoi ${ }^{1}$ and Pallavi Shah ${ }^{1}$
}

\author{
${ }^{1}$ Department of Veterinary Biotechnology, Indian Veterinary Research Institute (IVRI), \\ Izatnagar, Bareilly (UP) - 243122, India \\ ${ }^{2}$ Department of Molecular and Cellular Engineering, Sam Higginbottom University of \\ Agriculture, Technology, and Sciences (SHUATS), Prayagraj (UP) - 211007, India
}

*Corresponding author

\section{A B S T R A C T}

Key w o r d s
TP53, ELISA, PCR,
cloning, CMT,
Expression

Canine Mammary Tumour (CMT) is the most common malignancy of unspayed female dogs and is of potential importance as a model for human breast cancer. Mortality rate in female dogs is three times than that of human females with breast cancer due to lack of detection at an early stage. Therefore it is important to identify candidate biomarkers for canine mammary tumour with potential for disease diagnosis at early stages. Tumour antigen P53 (TP53) is well established marker for human breast cancer studies, however few studies have focussed on its characterization in CMTs. Therefore in this study immunodominant region in TP53 gene was amplified and cloned in prokaryotic expression vector. Further the conditions were optimized for the expression of the recombinant protein. The recombinant protein was purified using Ni-NTA affinity chromatography. The hyperimmune sera were raised in rabbits against the recombinant protein. In the hyperimmune sera, antibodies specific to TP53 were detected by Indirect ELISA, confirming the serological reactivity of the immunodominant region. The antibodies raised against canine TP53 will be useful in developing assays for detecting TP53 antigen in serum of dogs with cancers. Further the purified antibodies can also be utilized for detection of TP53 antigen in CMT tissues.

\section{Introduction}

The frequency of mammary cancer varies in different domesticated animals. Dog is the most frequently affected domesticated species having a prevalence more than three times than that in human females (Schneider, 1970).Canine mammary tumour (CMT) is the most prevalent cancer of female dogs exceeding 5 years of age (Davidson, 2003; Murphy, 2008; Salas et al., 2015), accounting above $40 \%$ of all tumour diagnosed (Sleeckx et al., 2011; Beck et al., 2013). Half of the mammary cancers are benign and can be treated by surgery alone while half are malignant and have the potential to 
metastasize, resulting in high death rates of bitches. Mammary cancer malignancy in dogs occurs mostly in unspayed female dogs which comprise about $52 \%$ of all neoplasms (Macewenand Withrow, 1996). The mortality rates in dogs suffering from canine mammary tumour (CMT) are more than three times than that of human mammary cancer (Egenvall et al., 2005; Shafiee et al., 2013). Thus CMT represents an important malignancy of dogs which provide ample scope for formulation of new methods for disease control and management.

The diagnosis of canine mammary tumours comprises of physical examination, conventional diagnostic procedures (complete blood profile, urine analysis, X-Ray of chest and abdomen, abdominal ultrasound, CT scan and lymph node examination), excisional biopsy or fine needle aspiration cytology (FNAC) etc. But these conventional diagnosis procedures are invasive and can diagnose the mammary tumours at a very late stage when the tumours start to metastasize and treatment becomes very difficult at this stage which results in high mortality.

If diagnosis can be done at an early stage (even before appearance of symptoms) then treatment can be very effective. Thus early detection of canine mammary cancer is an important factor associated with successful treatment. Recently the potential of serum cancer biomarkers for early diagnosis of cancer is being explored. Serum cancer biomarkers have been defined as molecules whose level in the serum can be monitored to indicate onset and progression of cancer. Tumours overexpress certain serum biomarkers like Tumours Associated Antigens (TAA) which can be used for diagnosis and progression of certain cancers at very early stage. For example, TAA CA125 is detected at high level in ovarian cancer (Bast et al., 2002), prostate specific antigen
(PSA) is detected in prostate cancer (Stephan et al., 2002) and HER-2 and MMP-9 are associated with mammary cancer (Lam et al., 2012; Yokota et al., 2001). TP53 is also called as p53, cellular tumour antigen p53, the guardian of the genome and tumour suppressor p53. It helps in preventing cancer formation and hence function as tumour suppressor. For this reason TP53 is also known as 'the guardian of the genome' as it helps in prevention of genetic mutation and preserve stability. About $50 \%$ of cancers have mutation of TP53 gene which results in inactivation of p53 pathway and results in accumulation of $\mathrm{p} 53$ proteins. It allows the detection of TP53 protein by a number of immunochemical procedures (Haga et al., 2011).

Though TP53 has been studied extensively in human cancer study but not much work has been done for studying TP53 as tumour associated antigen and early prognostic molecule in dogs. Data from molecular and clinical researches suggest that canine mammary tumour can be used as a model to study human breast cancer and vice versa. Canine mammary tumour imitates human breast cancer and many similarities are found at the molecular level including p53 suppressor gene mutations etc (Queiroga et al., 2011).

\section{Materials and Methods}

\section{Collection and histopathological analysis of tumour tissues}

Canine mammary tumour tissues used in the study were collected following surgical excision of tumour from clinical cases of CMT referred for surgery to the "Referral Veterinary Polyclinic', Indian Veterinary Research Institute (IVRI), Izatnagar, Bareilly, India. The tissues were fixed in $10 \%$ Neutral buffered formalin (NBF). 
Thereafter the tissues were paraffin embedded and $5 \mu \mathrm{m}$ sections were cut for histopathological examinations. The sections were stained by haematoxylin and eosin (H\&E) stain before examination under microscope for signs of malignancy

\section{Amplification and cloning of the TP53 gene}

Escherichia coli (E.coli) KRX cells (Promega, Madison, USA) were used in the study for gene cloning.RNA was isolated from CMT tissue sample by Trizol method as per the guidelines. Quantification of RNA was performed using Qubit RNA BR Assay Kit (Invitrogen, USA). Revert Aid cDNA synthesis kit (Fermentas, USA) was used to produce cDNA from total RNA as per the manufacturer`s protocol. The cDNA from CMT tissue sample was synthesised using Oligo (dT) primers, dNTPS, RNAase inhibitor, total RNA and reverse transcriptase in a total volume of $20 \mu \mathrm{l}$. The prepared cDNA was stored at $-80^{\circ} \mathrm{C}$ for further use. The forward and reverse primers were designed for amplification of C-terminal $750 \mathrm{bp}$ region for TP53 gene by using Premier 5.0 software (National Bioscience), analysed using oligoanalyser 3.1 and custom synthesised by Integrated DNA technologies (USA). The PCR was accomplished with a total of $50 \mu 1$ reaction mixture containing $25 \mu \mathrm{l} \mathrm{Kapa} \mathrm{Hi-}$ fidelity PCR master mix (2X), $1 \mu \mathrm{l}$ of $20 \mathrm{pM}$ each of forward and reverse primer and $3 \mu \mathrm{l}$ of template cDNA. The annealing temperature was optimised using gradient PCR machine (Veriti Thermocycler, Applied biosystems). For optimisation of annealing temperature, reaction mixture was divided into 5 tubes of $10 \mu \mathrm{l}$ each, which were subjected to different annealing temperatures $\left(53^{\circ} \mathrm{C}-61^{\circ} \mathrm{C}\right)$ in gradient PCR machine. The amplified PCR amplicon was gel purified using min-elute PCR purification kit (Qiagen, Hilden, Germany) as per manufacturer`s protocol. R.E digestion of PCR product and
pH6HTN His 6 HaloTag T7 Vector (Promega, Madison) was done using Apa I and $\mathrm{Xba}$ I restriction endonucleases (NEB, England) at $37^{\circ} \mathrm{C}$ for $2 \mathrm{hrs}$ to create complementary overhangs. The forward and reverse primers used for amplifying the $\mathrm{C}$ terminal region of TP53 gene were having the site for Xba I and Apa 1 at their 5'end. The purified PCR product and pH6HTN vector were ligated at $8^{\circ} \mathrm{C}-10^{\circ} \mathrm{C}$ overnight using T4DNA ligase (Promega, Madison) and were transformed into E.coli KRX competent cells and plated on LB plates containing $100 \mu \mathrm{lg} / \mathrm{ml}$ ampicillin. The recombinant colonies were identified by colony PCR and were further confirmed by plasmid PCR, RE analysis and sequencing.

\section{Expression and purification of recombinantTP53}

The recombinant plasmids were transformed into E. coli KRX cells following heat shock at $42{ }^{\circ} \mathrm{C}$ for 45 minutes. The cells were then plated on LB agar plate containing $100 \mu \mathrm{g} / \mathrm{ml}$ ampicillin and kept at $37^{\circ} \mathrm{C}$ overnight. Thereafter colonies were revived in LB medium for large scale expression and purification of recombinant protein. The conditions like IPTG concentration, induction temperature and time etc were optimised for expression of recombinant protein. Optimum expression of TP53 protein was observed when inoculum was induced for 6hrs with Isopropyl- $\beta$-d-thiogalactopyranoside (IPTG) and rhamnose at a final concentration of $1 \mathrm{mM}$ when $\mathrm{OD}_{600} \mathrm{~nm}$ reached 0.5 . The culture was pelleted after $6 \mathrm{hrs}$ of induction. The pelleted culture was solubilised with $8 \mathrm{M}$ urea, $60 \mu \mathrm{l}$ of lysozyme and $60 \mu \mathrm{l}$ of protease. $10 \mathrm{mg} / \mathrm{ml}$ of induced and uninduced culture were analysed using $12 \%$ sodium dodecyl sulphatepoly acrylamide gel electrophoresis (SDSPAGE) along with protein molecular weight marker (Biorad). Once the expression was confirmed, recombinant protein was purified 
by sonicating and loading the supernatant onto His Trap FF affinity column packed with $500 \mu \mathrm{l}$ of Ni-NTA agarose (Qiagen, Hilden, Germany). The impurities were then washed by wash buffer containing $100 \mathrm{mM} \mathrm{NaH} \mathrm{PO}_{4}$, $10 \mathrm{mM}$ tris- $\mathrm{Cl}$ and $8 \mathrm{M}$ urea $(\mathrm{pH} 6.3)$ and finally the recombinant protein was eluted in elution buffer containing $100 \mathrm{~m} \mathrm{M} \mathrm{NaH} \mathrm{PO}_{4}$, $10 \mathrm{mM}$ tris- $\mathrm{Cl}$ and $8 \mathrm{M}$ urea $(\mathrm{pH} 4.6)$. The recombinant TP53 protein was dialysed against PBS using dialysis tubing (Sigma Aldrich, USA) and analysed for concentration by using Qubit fluorometer (Life technologies, USA).

Characterization of the polyclonal sera raised against TP53 in rabbit

Hyperimmune serum was collected from rabbit procured from Livestock Animal Research (LAR) section, IVRI, Izatnagar. Prior to immunization, pre-immune serum was collected and immunization of recombinant protein mixed with Freund's complete adjuvant (FCA) was done at day 1 . At $7^{\text {th }}$ and $14^{\text {th }}$ day, immunisation was done using recombinant protein mixed with Freund's Incomplete Adjuvant (FIA).

Hyperimmune sera were collected at $21^{\text {st }}$ day. Indirect ELISA was performed for detection of antibodies against TP53 by using recombinant TP53 as coating antigen and plate was kept overnight at $4^{\circ} \mathrm{C}$. Blocking was done with 5\% skimmed milk and then washed with PBS containing $0.05 \%$ tween. Primary antibodies (serum samples) were diluted 2 folds (1:400, 1:800, 1:1600, 1:3200, $1: 6400,1: 12800,1: 25600)$ in $1 \%$ BSA and added in each well. Plates were then washed and secondary antibody (anti-dog) HRPO conjugate (Sigma, Aldrich) was diluted 1:10000 and $10 \mu \mathrm{l}$ was added in each plate. Plates were again washed and $100 \mu \mathrm{OPD}(\mathrm{o}-$ Phenylenediamine Dihydrochloride) was added along with $\mathrm{H}_{2} \mathrm{O}_{2}$. Reaction was stopped with $1 \mathrm{M} \mathrm{H}_{2} \mathrm{SO}_{4}$ and microplate reader (BioRad, USA) was used to measure optical density at 492 nm (Furuya et al., 2013).

\section{Results and Discussion}

Histopathological analysis of tumour tissue from the case of CMT revealed that the tissue was malignant and was classified as solid carcinoma. Figure 1 shows microscopic image of H\&E stained CMT tissue. The tissue was used for RNA isolation and amplification of TP53 gene. As explained earlier, TP53 gene was amplified by PCR and the amplified gene showed band size of $750 \mathrm{bp}$ upon agarose gel electrophoresis (Fig 2). Cloning of amplified TP53 gene was done in pH6HTNHis6 Halo Tag T7 prokaryotic expression vector (Promega). The recombinant clones were confirmed by PCR, $\mathrm{RE}$ analysis and sequencing. RE digestion of plasmid isolated from recombinant colony was performed using Xba 1 and Apa 1 restriction endonuclease, insert of size corresponding to TP53 gene (750 bp) was released from the vector.

The recombinant plasmid, pHTN-TP53 was transformed in E. coli KRX cells. Optimum expression of TP53 was observed upon induction of recombinant plasmid transformed cells for 6 hours with 1 M IPTG. Upon SDS PAGE analysis of induced and uninduced lysates, 60 Kilo Dalton $(60 \mathrm{KDa})$ band corresponding to size of recombinant TP53 protein with halo tag was observed as shown in fig 3.

Histrap FF column (Qiagen, Germany) was used to purify the recombinant TP53 protein. When the eluted protein was run $12 \%$ SDSPAGE, band of size $60 \mathrm{KDa}$ corresponding to recombinant TP53 with the halo tag was observed. (fig 4). The antibodies raised in rabbit against recombinant TP53 were analysed for their immunoreactivity with the 
recombinant TP53 protein by Indirect ELISA. Serial two fold dilutions of hyperimmune sera reacted specifically with the recombinant protein resulting in a linear curve as shown in figure 5. The reaction was found to be specific and no signal was observed with control serum. Though TP53 has been studied extensively in human cancer study but not much work has been done for studying TP53 as tumour associated antigen in dogs. The study allowed characterization of TP53 gene and to access its over expression in canine mammary cancer allowing the use of TP53 as a prognostic factor in early detection of cancer. Further the protein was expressed in E.coli and purified protein was isolated successfully. The recombinant TP53 from dog offers new perspective for its use as prognostic factor, development of vaccines and drug target in cancer.

Histopathological analysis of $\mathrm{H} \& \mathrm{E}$ stained tumour tissue revealed that the tumour was malignant and was classified as solid carcinoma (Fig.1).

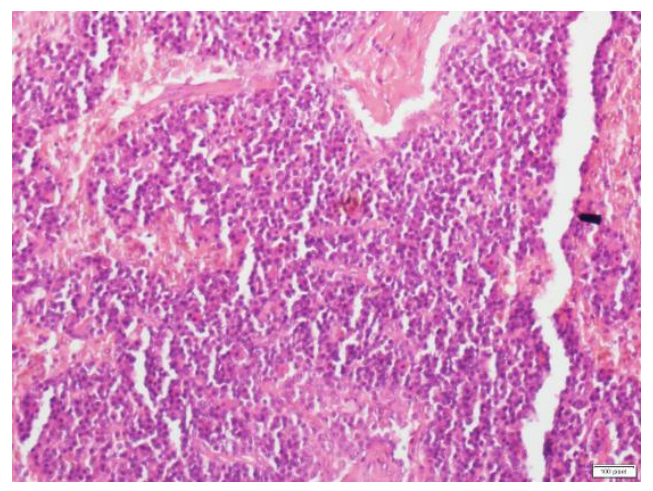

Fig.1 Histopathological analysis of H\&E stained tumour tissue

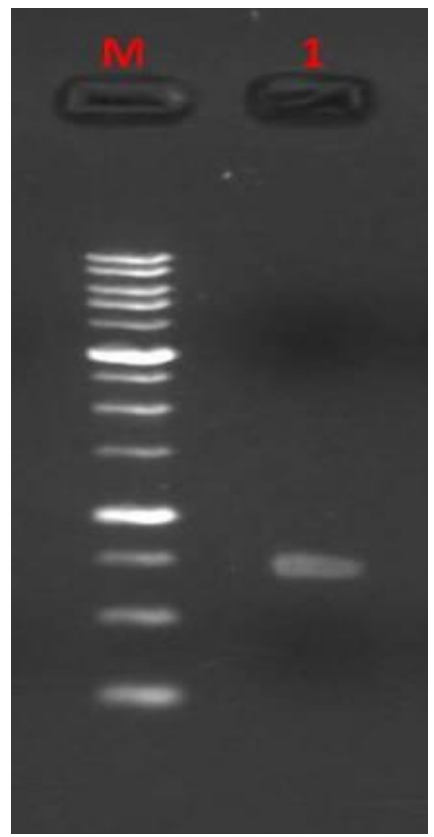

Fig.2 Amplification of TP53 gene from CMT tissue

Lane (M) 100 bp DNA ladder. Lane (1) Amplified 750 bp TP53 gene PCR products 


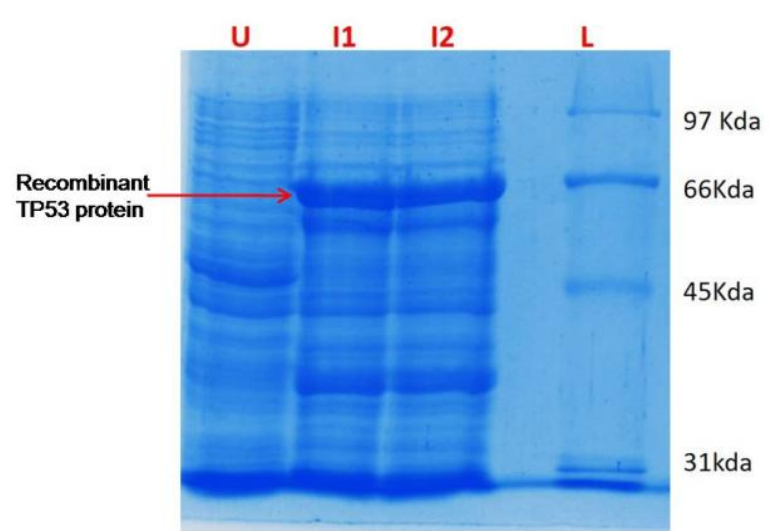

Fig.3 SDS-PAGE Analysis of uninduced and induced recombinant cultures showing expression of TP53 protein in E.coli

Lane U) Lysate from uninduced bacterial cultures

Lane I1) Lysate from recombinant cultures indued with $1 \mathrm{mM}$ IPTG

Lane I1) Lysate from recombinant cultures induced with $0.8 \mathrm{mM}$ IPTG

Lane L) Unstained low range protein molecular weight marker

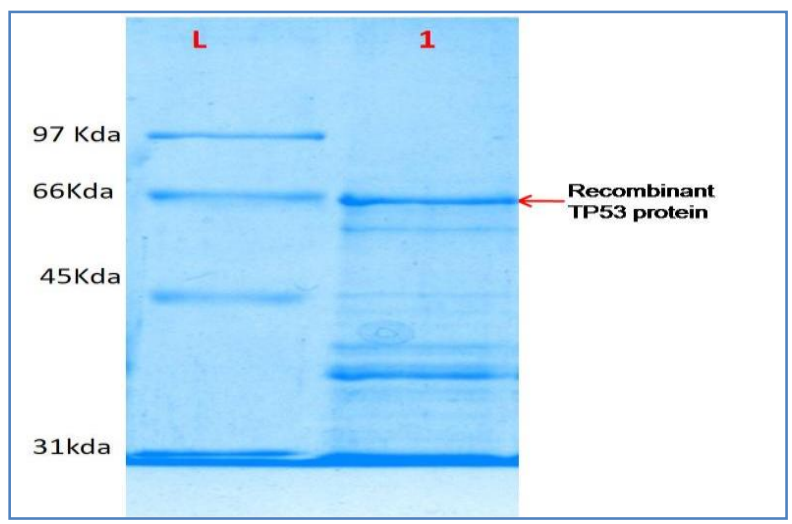

Fig.4 SDS PAGE analysis of purified recombinant TP53 protein Lane 1) Purified TP53 protein (60kda)

Lane L) Unstained low range protein molecular weight marker

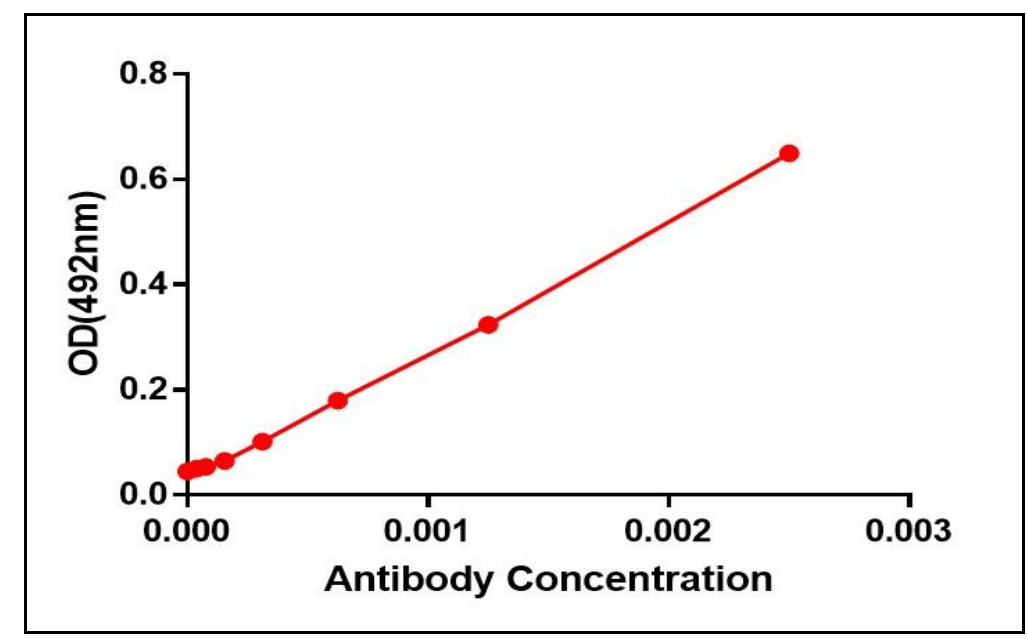

Fig.5 ELISA reactivity of TP53 protein with serial dilutions of rabbit hyperimmune sera 
In this study canine TP53 was successfully cloned and expressed in prokaryotic expression system. The antibodies raised against the protein in rabbits reacted specifically with the protein, showing the presence of $\mathrm{B}$ cell epitope regions in the protein of interest. In future purified antibodies raised against canine TP53 can be utilized for developing assays for detecting TP53 antigen in serum, as well as, tissues of dogs with cancers. Till now many studies have been done but the quantification of TP53 in case of CMT is not in routine practice. Thus more elaborate research should be performed as TP53 has a great potential to be used as tumour marker, tumour vaccine antigen and molecular target of therapeutic drugs.

\section{Acknowledgements}

The authors are thankful to Director, IVRI, Izatnagar for providing necessary infrastructure and facilities to carry out this research work.

\section{References}

Bast, R., Urban, N., Shridhar, V., Smith, D., Zhang, Z.and Skates, S. 2002. Early detection of ovarian cancer: promise and reality. Cancer Treat.107:61-97

Beck, J.,Hennecke, S., Bornemann-Kolatzki, K., Urnovitz, H., and Neumann, S. 2013. Genome aberrations in canine mammary carcinomas and their detection in cell-free plasma DNA. PLoS One

Davidson, EB. 2003. Treatment of mammary tumours in dogs and cats. Proceedings of North American Veterinary Conference. 66:1036-1038

Egenvall, A., Bonnett, BN., Ohagen, P., Olson, P., Hedhammar, A., and Euler, HV. 2005. Incidence of and survival after mammary tumours in a population of over 80,000 insured female dogs in Sweden from 1995 to 2002. Prev. Vet. Med. 69:109-127

Haga, S., Nakayama, M., Tatsumi, K., Maeda, M., Imai, S., Umesako, S., Hilgers, J., andSarkar, NH. 2001. Overexpression of the p53 Gene Product in Canine Mammary Tumors. Oncology reports8 (6), 1215-1219

Lam, L., McAndrew, N., Yee, M., Fu, T., Tchou, J.C., and Zhang, H. 2012. Challenges in the clinical utility of the serum test for HER2 ECD. Biochemica et Biophysica Acta. 1826:199-208

Lopuszynski, W.,Szczubial, M., and Komsta , R. 2010. Prognostic status of p53 protein accumulation in canine malignant mammary tumours. Bull Vet inst Pulawy 54, 105-1111

MacEwen, E.G., and Withrow, S.J. 1996. Tumors of the mammary gland. In: Withrow, s.j. E.G. (Eds), Small Animal Oncology. Saunders Co., Philadelphia, PA. 356-372

Murphy, S. 2008. Mammary tumours in dogs and cats. Practice. 30:334-339

Queiroga, F.L., Raposo, T., Carvalho, M.I., Prada, J., and Pires, I. 2011. Canine mammary tumours as a model to study human breast cancer; Most recent findings. In vivo, 25:455-465

Salas, Y., Marquez, A. Diaz, D and Romero L. 2015. Epidemiological Study of Mammary Tumors in Female Dogs Diagnosed during the Period 20022012. A Growing Animal Health Problem. PLoS ONE. 10(5)

Schneider, R. 1970. Comparison of age, sex and incidence rates in human and canine breast cancer. Cancer. 26:419426

Shafiee, R., Javanbakht, J., Atyabi, N., Kheradmand, P., Khedarmand, D., Bahrami, A., and Khadivar, F. 2013. Diagnosis, classification and grading 
of canine mammary tumours as a model to study human breast cancer: Anclinico-cytohistopathological study with environmental factors influencing public health and medicine. Cancer Cell Int. 13:79

Sleeckx, N., Rooster, H., Kroeze, EJBV., GinnekenC van and Brantegem, L. 2011. Canine mammary tumours,an overview. Reprod. Domest. Anim. 46:1112-1131

Stephan, C., Diamandis, E.P., Rittenhouse, H.G., Lein, M., and Loening, S.A.
2002. Prostate-specific antigen in molecular forms, and other kallikrin markers for detection of prostate cancer. Urology 59:2-8

Yokota, H., Kumata, T., Taketaba, S., Kobayashi, T., Moue, H., Taniyama, H., Hirayama, K., Kagawa, Y., Itoh, N., Fujita, O., Nakade, T., and Yuasa, A. 2001. High expression of $92 \mathrm{kDa}$ Type IV collagenase (MMP9) in canine mammary adenocarcinoma. Biochemica et Biophysica acta. 1568:7-12

\section{How to cite this article:}

Shumaila Khan, Sonal Saxena, Poonam Singh, Nupur Dutta, Sameer Srivastava, Purnima Gogoi and Pallavi Shah. 2020. Expression and Evaluation of Serological Reactivity of Recombinant TP53 Canine Mammary Tumour Associated Antigen. Int.J.Curr.Microbiol.App.Sci. 9(07): 814-821. doi: https://doi.org/10.20546/ijcmas.2020.907.094 